International Journal of Child, Youth and Family Studies (2014) 5(3): 466-492

\title{
PARENTING STYLES AND OFFSPRING'S POLYSUBSTANCE USE IN BIOLOGICAL AND ADOPTIVE FAMILIES
}

\section{Nozomi Franco Cea and Gordon E. Barnes}

\begin{abstract}
From the perspective of socialization theory, one aspect of the family environment that has been hypothesized to be one of the strongest predictors of offspring's substance use is parenting style. This study examined the associations between offspring's perspectives of fathers' and mothers' parenting styles and the polysubstance use (PSU) in biological and adoptive families by youth and young adults. Long-term influences of the parenting styles of fathers and mothers were also investigated by using longitudinal data on offspring's PSU. Results of structural equation modelling analyses showed that offspring's time 1 PSU scores were significantly related to both positive and negative parenting styles, whereas overall time 2 PSU scores were more strongly related to offspring's age and gender than parenting. In both time 1 and time 2 models, different paths were found to be significant for paternal and maternal parenting models. Only adopted offspring PSU scores were found to be significantly influenced by parenting of both fathers and mothers when offspring became older. These findings confirm: (a) the uniqueness and potential vulnerability of adopted offspring in relation to PSU, (b) the difference in influence for fathers' and mothers' parenting on offspring's PSU, and (c) the long-term influences of parenting style on adopted offspring.
\end{abstract}

Keywords: parenting, polysubstance use, young adult, adopted, longitudinal

Acknowledgements: The first wave of data collection of the Vancouver Family Survey (VFS) was funded by Health Canada through the National Health Research and Development Program (NHRDP). The second wave was funded by a Community Alliance for Health Research grant from the CIHR and a New Emerging Team grant (\#RA79917) funded by CIHR (Institutes of Neurosciences, Mental Health and Addiction, Institute of Aboriginal People's Health, Institute of Human Development, Child and Youth Health), the Canadian Centre on Substance Abuse, and the Canadian Tobacco Control Initiative. Resources in support of this study were also provided by the Centre for Addiction Research of British Columbia.

Nozomi Franco Cea (the corresponding author) is a Ph.D. student in the School of Child and Youth Care and the Centre for Addiction Research of British Columbia at the University of Victoria, P.O. Box 1700, STN CSC, Victoria, British Columbia, Canada, V8W 2Y2. E-mail: nkido@uvic.ca

Gordon E. Barnes, Ph.D. is a professor in the School of Child and Youth Care, a Research Scientist with the Centre for Addiction Research of British Columbia, and Faculty Associate with the Centre for Youth and Society, at the University of Victoria, P.O. Box 1700, STN CSC, Victoria, British Columbia, Canada, V8W 2Y2. E-mail: gbarnes@uvic.ca 
The abuse and misuse of a wide variety of illicit substances have been a major public health problem all over the world (Kendler et al., 2012). Research in the field of substance use has focused on the use of specific single substances such as tobacco (smoking), alcohol, marijuana, etc. However, an increasing number of studies have been reporting that polysubstance use (PSU) is a growing problem in the general population (e.g., Schensul, Convey, \& Burkholder, 2005). There is an increasing awareness and recognition of PSU and problems associated with this behaviour (e.g., Pape, Rossow, \& Storvoll, 2009). More importantly, population-based research conducted in the United States and Canada has shown that PSU is common in the general youth population (e.g., Brière, Fallu, Descheneaux, \& Janosz, 2011).

From the perspective of socialization theory, the environment that parents create and develop through parental socialization (i.e., parenting) has been hypothesized to be one of the strongest predictors of youth and young adult PSU (e.g., Barnes, Hoffman, Welte, Farrell, \& Dintcheff, 2006). In the last three decades, a significant number of studies have investigated the predictors of initiation, trajectories, and severity of youth and young adults PSU. Predictors examined have included families' socio-economic status (e.g., Patrick, Wightman, Schoeni, \& Schulenberg, 2012), parental influences (e.g., Bahr \& Hoffmann, 2010), peer influences (e.g., Barnes, Jansson, \& Stockwell, 2011), behavioural genetic factors (e.g., Creemers et al., 2011), and psycho-social development (e.g., Jones, 2011).

It has been commonly assumed that as children get older, parents begin to play a less important role, and other influences such as peers and media trends become more powerful forces in directing and leading young people's behaviours (Lac, Alvaro, Crano, \& Siegel, 2009). Due to this assumption, even parents themselves might doubt their importance and feel less confident. However, evidence from two studies indicate that parents do, in fact, play an important role in terms of the development of their adolescent offspring (Hair, Moore, Garrett, Ling, \& Cleveland, 2008; Padilla-Walker, Bean, \& Hsieh, 2011). Moreover, a number of researchers in the field of behavioural genetics have been reporting on the combinations and interactions between parental behaviours, heritability (genetic influences), and shared (family) environmental influences (e.g., Creemers et al., 2011; Kendler et al., 2012).

\section{Parenting Styles and Polysubstance Use}

Family socialization is a broad concept that consists of numerous components that can have an important role in predicting offspring substance use patterns. For example, based on their systematic review of longitudinal studies of adolescent alcohol use, Ryan, Jorm, and Lubman (2010) identified that parental modelling, monitoring, parental disapproval of drinking, general discipline, and parental support, as well as parent-child relationship quality and communication, were significant factors for both initiation and the levels of drinking in late adolescence and young adulthood. Other studies have examined different aspects of family socialization or similar aspects under different terms such as cohesion, overprotection, care, warmth, autonomy granting, etc. (e.g., Barnes et al., 2006; Creemers et al., 2011; JiménezIglesias, Moreno, Granado-Alcón, \& López, 2012; Latendresse et al., 2010), and have found that those aspects of parenting are significantly associated with adolescent substance use. 
Another common way to examine the influence of parenting patterns on offspring outcomes is to employ the four general categories of parenting styles: authoritative, authoritarian, permissive, and neglectful (Bahr \& Hoffmann, 2010; Patock-Peckham, King, Morgan-Lopez, Ulloa, \& Moses, 2011; Piko \& Balázs, 2012b; Zeinali, Sharifi, Enayati, Asgari, \& Pasha, 2011). Research by Bahr and Hoffmann (2010) shows that authoritative parenting (highly demanding, highly responsive, monitoring closely, providing high levels of support and warmth) diminished the likelihood of adolescents choosing to engage in risky forms of substance use, even when they had friends who use alcohol or other drugs, thus showing that parents can be a significant influence on the risk-taking behaviours of their adolescents.

The influence of parents, and particularly fathers, has been highlighted by Padilla-Walker et al. (2011). This study highlighted the importance of positive fathering - suggesting the unique importance of fathers, particularly in relation to externalizing and internalizing behaviours (Padilla-Walker et al., 2011). In other words, the quality of the parent-adolescent relationship matters, even for adolescents beginning the transition to adulthood. These parenting patterns were not only predicted by earlier parenting, but appeared to represent distinct and important aspects of parenting during adolescence (Hair et al., 2008). This suggests that despite the increased distance between children and parents during adolescence, parenting continues to be strongly related to adolescents' personal characteristics and behaviours. Further evidence for this is discussed below:

Parenting, peer influences, and PSU. Although several studies have suggested that association with deviant peers may play a more important role in adolescents' polysubstance use than parents, more research has found that parenting styles remain a primary determinant of polysubstance use across adolescence (Cleveland, Feinberg, \& Greenberg, 2010), and parents still have a significant influence on their offspring's substance use after controlling for association with deviant peers (Barnes et al., 2006; Dorius, Bahr, Hoffmann, \& Harmon, 2004; Piko \& Kovács, 2010). Additional support for the importance of parental influence is provided by Grace Barnes and her colleagues (2006) who examined six waves of longitudinal data from 506 adolescents about their alcohol use, illicit drug use, delinquency, parenting styles (support, communication, cohesion, and monitoring) and peer deviance. Barnes et al. concluded that the effects of parenting do indeed buffer the influence of peer deviance on the upward trajectory of these problem behaviours during adolescence. There is also strong evidence that "positive parenting" (i.e., high levels of parental knowledge or low levels of inconsistent discipline) is linked to the types of friends that adolescents associate with, further protecting their child from engaging in substance use (Cleveland, Feinberg, Osgood, \& Moody, 2012). Taken together, research indicates that parents serve a vital function in that they may decrease, or even increase, the likelihood of their offspring's initiation and trajectories of substance use even when offspring get older (Lac et al., 2009). Additionally, based on their review of research on parental styles and substance use, Becoña et al. (2012) concluded that "an adequate parental style helps to cushion the influence of peers or of personal problems that may be related to substance use.... There is no doubt that parental styles can increase the risk of drug use or help to protect against it” (p. 2).

Monitoring. Monitoring is a concept widely used to describe a parental child rearing strategy, yet it is not uniformly defined. In existing studies, monitoring contains various 
components, and monitoring itself is an aspect of various concepts of parenting; thus, a variety of measures have been utilized to assess this construct. It has, for instance, been defined as parental knowledge of children's activities/whereabouts/peer relationships (e.g., Dorius et al., 2004; Bohnert, Anthony, \& Breslau, 2012; Patock-Peckham et al., 2011), discipline, that is parents' use of clear and consistent rules (Cleveland et al., 2010), control or parents' attempts to direct, guide, and modify behaviour in their children - including suggestions, instructions, commands, rules, threats, and punishments (e.g., Dorius et al., 2004), and/or "a way of transmitting behavioural norms for children” (Piko \& Balázs, 2012a, p. 353). Moreover, this commonly used concept has been reinterpreted by numerous researchers over the last decade. For instance, Jimenez-Iglesias and her colleagues (2012) defined monitoring as a bidirectional communication and relationship between parents and offspring. Meanwhile, Kerr, Stattin, and Burk (2010) interpreted it as a twofold parental knowledge gained via both parental solicitation (parents' tendencies to actively seek information about their children) and offspring's disclosure of information. In spite of this inconsistency, monitoring (or its absence) is the most frequently studied and identified predictor for adolescents’ substance use (e.g., Barnes et al., 2006; Bohnert et al., 2012).

According to the contemporary studies, parental monitoring (particularly knowledge of children's whereabouts) was the most significant protective factor for adolescents for smoking, binge drinking, and marijuana use (e.g., Piko \& Kovács, 2010). Jiménez-Iglesias et al. (2012), who conducted their study with 15,942 Spanish adolescents, indicated that perceived parental knowledge of a young person's whereabouts was negatively associated with substance use and had, in most cases, greater importance for the prediction of consumption than the adolescents' gender. Therefore, perceived parental knowledge was, along with age, the most relevant variable in substance use. The literature on parental monitoring, therefore, suggests that such monitoring, although used less as an adolescent gets older, is a highly significant method of preventing an upward trajectory of substance use even if such a trajectory has already begun, and can be an important deterrent for substance use in older adolescents (Barnes et al., 2006). Still, although parenting style is clearly important, it is not the only factor that plays a role in the development of substance misuse issues. Also significant are inherited genetic traits.

\section{Behavioural Genetic Approach}

In the field of substance use studies, the behavioural genetic approach makes its contributions by studying the inheritance of behavioural traits through twin studies or adoption studies, and through the rapidly evolving new field of molecular genetics (Plomin \& Colledge, 2001). In fact, substance use is one of the most active areas of behavioural genetic research (Dick, Prescott, \& McGue, 2009).

Quantitative genetics. Twin studies typically look at influences of genetic, shared environmental, and non-shared environmental factors. In their twin study of adolescent substance use, Derringer, Krueger, McGue, and Iacono (2008) found weak heritability early in adolescence, but increasing heritability later in adolescence. In other words, adolescents are more influenced by environmental factors than adults, but over time, heritability becomes more significant, especially if environmental factors have not assisted in mitigating heritable issues. Further, several studies found that the strongest genetic influence has generally been found for heavier stages of substance use, and the relatively stronger influence of shared environmental 
International Journal of Child, Youth and Family Studies (2014) 5(3): 466-492

factors has been found on initiation, use, and non-diagnostic problematic substance use (Creemers et al., 2011; Derringer et al., 2008; Dick et al., 2009).

Molecular genetics. By employing the molecular genetic strategy, Ducci et al. (2011) examined the developmental change in gene effect by looking at the role of genetic variation within two gene-clusters on smoking in adolescents and mid-adults. Their findings suggested that these gene-clusters were involved in different stages of the process leading to nicotine addiction. One cluster was found to have a significant impact on smoking in adolescence (initiation and novelty seeking), but its impact declines with age and becomes undetectable in mid-adulthood. The other cluster was found to be significant for the mid-adult sample only. In other words, this gene-cluster impacts on continuation of smoking and/or increasing severity, but not on initiation. This study shows that different gene-clusters may affect behavioural outcomes differently at different points in our lifespan (Ducci et al., 2011).

Gene-environment interaction. While some behavioural genetic studies have been providing strong evidence for the importance of environment, it is now widely accepted that both genes and the environment play an important role in predicting substance use and dependence (Plomin \& Colledge, 2001), and these "genetic and environmental influences are likely to combine in complex ways” (Dick et al., 2009, p. 445). Gene-environment interaction implies that environmental stimuli can modify the importance of genetic influences on substance use.

Creemers et al. (2011) investigated gene-environment interactions in adolescence. They found that carrying genetic risk markers was not directly related to adolescents' substance use, but certain parenting styles were. Overprotection increased the risk of regular alcohol use, whereas the risk of cannabis use was enhanced by parental rejection, and buffered by emotional warmth (Creemers et al., 2011). These findings confirmed that "some environments exacerbate the expression of genetic predispositions, whereas others are protective” (Dick et al., 2009, p. 445).

Although new knowledge is constantly being added to our understanding of geneenvironmental interactions, findings from existing studies about adopted offspring, particularly their substance use patterns and/or overall well-being are not consistent or conclusive. For example, Fergusson, Lynskey, and Horwood (1995) reported that adopted children had a higher rate of substance use behaviours than children from biological families. However, the Colorado Adoption Project found that adoption status did not appear to be a predictor of substance use in adolescence (Wadsworth et al., 1997). More recently, Kendler et al. (2012), in their large-scale adoption studies of substance use, found evidence for gene-environment interaction even though their initial aim was not to find out whether adopted youth were at higher risk than their biological counterparts. Thus the findings of Kendler and colleagues show that adopted children with a high genetic risk for substance misuse are more sensitive to the deleterious effects of adverse family environments than those with a low genetic risk. In other words, genetic effects on substance abuse were "less potent in low-risk than in high-risk environments" (Kendler et al., 2012, p. 695). 
International Journal of Child, Youth and Family Studies (2014) 5(3): 466-492

\section{Challenges (Gaps) in the Current Parenting-PSU Studies}

Mother/father parenting. Mothers' care-giving behaviour and/or “mothering” are often considered as “parenting” behaviour as a whole (Hair et al., 2008; Latendresse et al., 2010). Additionally, most studies examining parenting styles and influences examine these variables with mothers and fathers lumped together with the word "parents" at the item level (e.g., Barnes et al., 2006; Patock-Peckham et al., 2011). For example, mothers who participate in research are often asked to report on the parenting strategies of the children's fathers. Research has demonstrated, however, that reports of paternal parenting differ for mothers and fathers (Mikelson, 2008, as cited in Pougnet, Serbin, Stack, \& Schwartzman, 2011). Further, several studies have found that mothering had greater influences than fathering; however, they also suggested that separating mother and father variables could provide more nuanced insights into the influence of parenting (e.g., Patock-Peckham et al., 2011). One of the earliest studies of mother/father parenting, conducted by Bogenschneider, Wu, Raffaelli, and Tsay (1998) found different aspects of parenting styles to be significant for mothers and for fathers. Mothers' responsiveness was found to be associated with adolescents' closeness to and relying on peers over parents, which, in return, predicted adolescents' substance use. Whereas, fathers' closer monitoring was directly associated with lower substance use, with stronger effects among fathers' more disapproving values regarding adolescents' alcohol use (Bogenschneider et al., 1998).

Today, fathers' influence and unique parenting functions are receiving more attention such that fathering variables are now more often included and fathers are also participating more frequently as informants (participants) in more studies (Hair et al., 2008). This inclusion of fathers has generated a variety of findings:

1. Dorius et al. (2004) showed that only closeness to father moderated the association between peer substance use and adolescent marijuana use. Closeness to mother and parental support (mother/father not separated) were found not significant. These findings suggested that during adolescence, father involvement may be particularly important in helping adolescents resist peer pressure to use drugs (Dorius et al., 2004).

2. Patock-Peckham et al. (2011) found that for sons, only mothers' low level of monitoring was indirectly linked to alcohol-related problems through high impulsiveness, whereas, for daughters, only fathers' monitoring was directly and indirectly linked to alcoholrelated problems through impulsiveness.

3. Piko and Balázs (2012b) conducted a study on the role of authoritative parenting style (responsiveness and demanding-ness) in adolescents' depressive symptomatology. They found that, for boys, only mothers' responsiveness was a significant predictor. For girls, however, fathers' responsiveness and demanding-ness were both found to be significant protective factors (Piko \& Balázs, 2012b).

These studies showed the importance of parental gender difference as well as the importance of opposite sex parental influence (Patock-Peckham et al., 2011; Piko \& Balázs, 2012b). We believe that we must recognize that the style of child rearing may vary for father and mother, and that even the same parenting style can affect offspring differently depending on which parent uses which particular parenting styles. Therefore, the effect of the different styles of both father and mother need to be studied further and more in-depth. 
Age. Also important to our understanding of the impact of parental factors on the development of substance abuse issues is the age of the child. As Hair et al. (2008) stated, it is still unknown or not well studied whether or how these parental factors influence substance use behaviours for older adolescents and young adults because most of the studies are cross-sectional and tend to focus only on young adolescents (Hair et al., 2008). Based on their review of behavioural genetic studies, Dick et al. (2009) also pointed out that the heritability estimates are consistently higher in adulthood than in childhood/adolescence and that the importance of different environmental factors also may vary across the lifespan. Therefore, the developmental stage (age) of the participants appeared to be of critical importance.

One of these environmental factors, parental influence, is widely thought to lessen in adolescence (Patock-Peckham et al., 2011). To challenge this assumption, Patock-Peckham and colleagues explored the possibility that parental influences and the effects of adequate parenting styles may extend into "emerging adulthood", a stage in which the parents may not always be present to engage in active monitoring. Based on their study of university students, they found that parental monitoring reduces alcohol-related problems when offspring may be beginning to show signs of independence (Patock-Peckham et al., 2011). Given these findings, we suggest that there is a need to study these relationships longitudinally, and to include older offspring (youth as well as young adults).

In summary, numerous studies provide evidence that parenting directly affects offspring's substance use, and also buffers the influence of peer deviance. Various parenting components and behaviours are found to be important protective or risk factors. There is growing recognition of the importance of behavioural genetic studies in this topic, which investigate the effects of both heritable and environmental factors on substance use and their interaction effects. Despite the fact that there is an extensive literature regarding the associations between parenting and substance use, studies which can control heritability (genetics), which investigate mother's parenting and father's parenting separately, and which consider these association in the lifespan by studying older offspring are scarce. Based on the consideration of the limitations and critiques of studies, the current study endeavours to deepen our understanding of the relationship patterns between parenting styles, offspring's adoption status, and substance use by examining this relationship at two points in the lifespan (ages 14 to 25 and 21 to 33). The main objective in the current study was to examine "how are parenting styles in the first 15 years of offspring's lives related to offspring's polysubstance use?” The conceptual model of the current study is presented in Figure 1. The following were the research questions of the current study:

1. Do fathers' and mothers' parenting styles influence offspring differently?

2. Do parenting styles influence biological offspring and adopted offspring differently?

3. Do parenting styles have significant influences on offspring polysubstance use at adolescence (time 1) and later in life - young adulthood (time 2)?

\section{Method}

The data for the current study are taken from the Vancouver Family Survey (VFS). The VFS was conducted as a two wave longitudinal survey in Vancouver, British Columbia, Canada. The primary objective in the VFS was to examine the associations between the family 
International Journal of Child, Youth and Family Studies (2014) 5(3): 466-492

environment and the risk for substance use in biological and adoptive families in a general population sample (Barnes, Murray, Patton, Bentler, \& Anderson, 2000).

\section{Participant Selection}

In the original design for the Vancouver Family Survey (VFS), Gordon Barnes, David Patton, and Sheila Marshall proposed to screen over 100,000 families to identify a sample of intact families with children in the 14 to 25 age range living at home (Barnes, Patton \& Marshall, 1997). The sample for the data collection was identified through a directory of telephone listings in the Greater Vancouver area. The data collection was restricted to intact families to allow an examination of the influence of both parents on the development of offspring. Children in the adopted families had to be adopted before the age of five and most adoptions occurred early in the first year of life. The sample excluded adoptive families where there existed any biological relationship with one of the parents. The participants were also restricted to respondents who were fluent enough in English to answer the questionnaires.

In the end, this process yielded a large $(n=5,120)$ sample of biological families eligible for participation, but only 177 adoptive families. Biological families were then selected at random for recruitment into the study, along with all of the identified adoptive families (Barnes et al., 1997). Families were contacted by telephone and an attempt was made to arrange a visit to each family to administer questionnaires to both parents and the youngest child in the 14 to 25 age range. Families were only included if all three family members were willing to participate. This procedure yielded data on a sample of 477 biological families and 75 adoptive families (participation rate of 53\%). Due to the fact that the screening process was very costly, the recruitment strategy was expanded to include recruitment through newspaper advertisements and referrals. This process produced an additional 57 adoptive families. Demographic comparisons were made between the random and non-randomly selected adoptive families. There were no differences between these groups except on mothers' education (15 years of education versus 14 years in the random sample) (Barnes et al., 1997). In the process of data cleaning, three randomly selected adoptive families, one non-randomly selected adoptive family, and one biological family were dropped for not meeting the inclusion criteria of this study. This produced a final sample of 601 families at wave 1.

Beginning in 2003, follow-up data at wave 2 were collected for the young adult sample of participants in the VFS (now ages 21 to 33). A total of 215 females and 190 males $(n=405)$ were re-interviewed, either in person or by use of the mail-out method. This represented $67 \%$ of the participants originally tested in time 1 . The refusal rate for this project was $18 \%$ with the remaining $15 \%$ of the sample lost for other reasons including death or failure to locate the individual (Barnes, Anderson, \& Jansson, 2008). The final data was comprised of 328 offspring from biological families and 77 offspring from adoptive families. Data for time 1 participants who did not participate at time 2 were excluded from this analysis.

In the VFS, data on parenting patterns were collected in the first wave of interviews only. In the current study, only offspring's perspectives of parenting styles were analysed due to the fact that several parenting style variables were only available from offspring's perspectives in the VFS data set. Potentially significant variables, such as monitoring and coercion were not 
International Journal of Child, Youth and Family Studies (2014) 5(3): 466-492

included in the parents’ questionnaire.

\section{Measures}

Substance use. Alcohol consumption was measured with the Volume-Variability Index (Cahalan \& Cisin, 1968) report on alcohol consumption patterns in the past year. Based on responses to these questions, a score measuring the daily volume of alcohol consumption was calculated. Smoking scores were derived based on the number of days smoked and the average number of cigarettes consumed over the past 30 days. Marijuana and other illicit drug use (cocaine or crack, LSD, Speed, Heroin) were assessed by items regarding the frequency of use for these substances in the past 12 months. Marijuana was treated as a separate drug use item, and the other drugs were combined to form an "other illicit drugs" scale.

For both the first and the second wave of data collection, exactly the same scale items were administered and scores were calculated by the same procedure. Based on these four substance use data, the standardized Polysubstance Use (PSU) variables for each wave were created by researchers who were also analysing VFS data (M. Jansson, personal communication, November 28, 2011). These variables were created by using the following strategies: (a) compute standardized individual scores of alcohol use, smoking, marijuana and other drugs; (b) calculate average overall score based on these four individual standardized scores; and (c) standardize this overall average score.

Demographics. Age (14 to 25 at time 1 and 21 to 33 at time 2), gender, and adoption status were used for the current study as demographic predictors.

Parenting styles. Parenting style data consists of 10 parenting variables measured by three different measurement tools. All data on parenting styles were based on respondents' perspectives on their parents' parenting styles in the first 15 years of their lives.

Cohesion. Family cohesion defined as "the emotional bonding that family members have toward one another” (Olson \& Tiesel, 1991, p. 1), was assessed by utilizing the Family Adaptability and Cohesion Evaluation Scales II or FACES II (Olson \& Tiesel, 1991). It was a joint measure of "parents' cohesion” instead of father/mother separated cohesion. Test-retest reliability for the cohesion scale over a four week period is $r=.83$ (Olson \& Tiesel, 1991). In the VFS, internal consistencies for the cohesion scale were .88 (Barnes et al., 1997).

Care and overprotection. The Parker Parental Bonding Instrument or PBI (Parker, Tupling, \& Brown, 1979) was utilized for assessing care and overprotection. The PBI contains 13 items measuring parental overprotection and 12 items assessing parental care. High care is defined by affection, emotional warmth, empathy, and closeness. High overprotection has been defined as control, intrusion, excessive contact, and prevention of independent behaviour. Testretest reliability of the care and overprotection scales over a three week interval are $r=.74$ and $r$ $=.69$ respectively (Parker et al., 1979). In the VFS, offspring filled the instrument out twice, once for each parent. Internal consistencies of the care and overprotection scales were as follows: maternal care .90; paternal care .91; maternal overprotection .85; paternal overprotection .80 (Barnes et al., 1997). 
Support, monitoring, and coercion. Parental support and control (monitoring and coercion) items taken from Grace Barnes and Farrell's study (1992) were also completed by offspring. Mother and father support were separately measured, each consisting of four items. Mother and father coercion were also measured separately with three items each (Cronbach's alpha $=.52$ for mother coercion and .58 for father coercion). Monitoring consists of two items about "parents' monitoring” instead of father/mother separated items (Cronbach's alpha $=.71$ ); "how often did you tell your parents where you're going to be after school?" and "how often did you tell your parents where you're really going when you went out evenings and weekends?” (Barnes et al., 1997).

\section{Analysis Procedures}

The first step in the data analysis involved examining the patterns of perceived parenting styles and substance use in biological and adopted offspring. These patterns were examined with multivariate analysis of variance (MANOVA). The between-subject independent variables were offspring's gender, adoption status (biological vs. adoptive), and their interactions. In addition, the bivariate associations between predictors, parenting style, and the substance use dependent variables were calculated in order to determine which variables were correlated with each other and needed to be included in the further analysis.

The next step involved building a structural equation model by utilizing EQS 6.1 (Bentler, 2004) using the maximum likelihood solution. First, we looked at the measurement structures in each of the domains. We executed confirmatory factor analysis for parenting styles and substance use. The substance use measures seemed to fit together on a polysubstance use latent factor; however, since standardized composite PSU variable showed better overall fits in the later analysis, this variable was selected instead of the latent factor. In the proposed conceptual model (see Figure 1), the parenting style variables fit onto four latent factor variables: positive parenting (cohesion, monitoring, support, and care) by father; positive parenting by mother; negative parenting (coercion and overprotection) by father; and negative parenting by mother. However, the potentially most significant variables (monitoring and cohesion) were assessed by father/mother joint measures in the original VFS, hence, not available separately for father and mother; at the same time, we particularly wanted to test whether these variables fit onto both father and mother latent variables. Therefore, in the end, the mother and father models were built and examined separately. Both models contained monitoring and cohesion loaded on the latent factor - positive parenting. Coercion and overprotection variables each from father and mother were considered to be potentially negative parenting variables; however, these two variables did not fit well onto a joint latent factor. Therefore, these variables were examined as independent predictors in each model.

In the following stage, we began to build the structural pathways in the overall model. The pairwise covariance matrix was employed to handle missing data. The LaGrange and Wald test as well as the Comparative Fit Index (CFI) and the Root Mean Square Error of Approximation (RMSEA) guided us to add and subtract paths in the models until the model reached a satisfactory level. It turned out that this structural pathway model works for both time 1 and time 2 models as well as for both mother and father models. In the final stage of model 
International Journal of Child, Youth and Family Studies (2014) 5(3): 466-492

building, we employed the multiple group constraints model - adopted offspring group and biological offspring group, for all four models. To achieve a "good fit" in the constrained models, paths were modified and constrained paths were determined. Some non-significant paths were retained in models when they were significant in other models such as direct paths from gender to PSU and offspring age to PSU. Criteria used to judge the fit of a final solution included reaching a $\chi^{2}$ to degrees of freedom ratio of less than two to one, a CFI of over .90, and RMSEA of less than .10 (Byrne, 2012).

\section{Results}

\section{Comparisons between Biological and Adoptive Samples}

The results of the MANOVA (see Table 1) showed that in both parenting styles and substance use tests, there were significant multivariate between-subjects effects by adoption status (parenting: $F=2.30, p<.05$; PSU: $F=13.47, p<.001$ ); and gender (parenting: $F=2.44$, $p<.01$; PSU: $F=3.84, p<.05)$. The univariate ANOVAs showed that adopted offspring scored lower than biological offspring on cohesion $(F=7.24, p<.01)$ and monitoring $(F=10.17, p<$ .01 ), but higher on mother coercion $(F=4.93, p<.05)$, father coercion $(F=4.90, p<.05)$, time 1 substance use $(F=18.88, p<.001)$, and time 2 substance use $(F=22.03, p<.001)$. Males scored lower on cohesion $(F=4.34, p<.05)$, monitoring $(F=8.66, p<.01)$, and father care $(F=$ 6.38, $p<.05)$, but higher on mother coercion $(F=4.57, p<.05)$, father coercion $(F=5.56, p<$ $.05)$, and time 2 substance use $(F=7.36, p<.01)$. A significant "adoption status by gender" interaction occurred on cohesion $(F=7.86, p<.01)$, father support $(F=9.44, p<.01)$, and father care $(F=6.08, p<.05)$. Particularly interesting to note is the fact that presumably protective factors, such as cohesion, father support, and father care, were reported at significantly lower levels in the adopted male offspring (see Table 2). Based on T-tests, the gender differences noted in Table 2 were found to be significant in the adoptive group, whereas, there was no significant gender difference in the biological group.

\section{Correlational Analyses}

The correlations of the demographics and parenting styles with the polysubstance use measures are shown in Table 3. In both biological and adopted samples, high scores in PSU time 1 shows significant correlations with low scores in cohesion, monitoring, father care, and mother care. In addition, high mother support, low father coercion, and low mother coercion were significantly correlated with low PSU in biological offspring, whereas, in adopted offspring, neither coercion scores are significant, but high father support is. The difference between biological and adopted offspring was more noticeable at time 2. For biological offspring, no parenting styles had significant correlations with PSU except monitoring (high monitoring-low PSU), whereas, for adopted offspring, four parenting variables had significant correlation with PSU - cohesion, father support, father care, and mother care.

Moreover, adopted offspring data showed PSU to be significantly correlated with father support at both time 1 and time 2, but not with mother support at either time. Biological offspring data showed a significant correlation with mother support, but not with father support at time 1 . These correlations suggest that there are different influences of parenting from mothers 
International Journal of Child, Youth and Family Studies (2014) 5(3): 466-492

and fathers.

Lastly, both biological and adopted offspring data show significant correlations between time 1 and time 2 PSU. This implies that time 1 PSU is predictive of time 2 PSU; however, the aim of this study is to examine the influence of parenting over time, but not moderation and mediation effects of earlier PSU (time 1). Therefore, we decided to analyze time 1 and time 2 PSU in separate models and compare results. Based on these findings, the final version of the structural equation model analysis was determined to consist of four separate multiple group constrained models (i.e., paths for biological and adoptive groups were constrained to be the same) - time 1 father parenting, time 1 mother parenting, time 2 father parenting, and time 2 mother parenting.

\section{Multiple Group Constraints Model Analyses}

Once all four overall models - (a) time 1 father, (b) time 1 mother, (c) time 2 father, and (d) time 2 mother) - were found to fit the data reasonably - (a) CFI = 0.95 RMSEA = 0.08; (b) $\mathrm{CFI}=0.93 \mathrm{RMSEA}=0.10$; (c) CFI = 0.95 RMSEA = 0.08; and (d) CFI = 0.93 RMSEA =0.10, respectively - these models were tested as two-group (adoptive versus biological) constrained models. At first, the four models were tested for both biological and adoptive groups separately to make sure each model worked for both groups. This process also shows different patterns of significant paths between the two groups. Placing constraints on the structural paths means that these paths are the same in both groups. Therefore, differences in path coefficients between groups would make it necessary to remove the constraints on these paths. The LaGrange Multiplier Test guided us to release constraints when it was necessary. Results of the final structural equation models are presented in Figures 2, 3, 4, and 5. In the four models, the tested paths are the same even though the respective coefficients may differ. In these figures, unconstrained paths were displayed as bold lines and showed path coefficients for both the adoptive group (A) and the biological group (B). In the figures, only significant path coefficients are shown. If a path is constrained and not significant for both groups, a dotted line is shown.

Time 1 father parenting model. The fit indices for the solution of time 1 father parenting model were considered to be a "good fit" based on recommended criteria: $\chi^{2}=84.005$; DF $=44$; $\mathrm{CFI}=0.95$; RMSEA $=0.07 ; \mathrm{R}^{2}=0.18$ (see Figure 2 ). This model showed that gender was significantly associated with monitoring (low for male) and coercion (high for male) for both biological and adopted youth. For the adoptive group, gender was also significantly associated with all three positive parenting variables, whereas for the biological group it was only associated with overprotection (low in male). As expected, the independent monitoring variable and the father positive parenting factor were both found to be directly associated with PSU as protective factors for both biological and adopted offspring. The independent cohesion variable was a significant direct predictor for the adoptive group only. Father coercion was found to be a risk factor for PSU for the biological group only. One unexpected result occurred with father overprotection, which turned out to be a significant protective factor for both biological and adopted offspring. All five covariance paths (shown as curved arrows in the models) were significant for both groups.

Time 1 mother parenting model. The fit indices for the time 1 mother parenting model 
suggested a moderately good fit: $\chi^{2}=98.783 ; \mathrm{DF}=45 ; \mathrm{CFI}=0.93 ; \mathrm{RMSEA}=0.08 ; \mathrm{R}^{2}=0.15$ (see Figure 3). This model shows that the predictor patterns were relatively similar to those found in the father model. However, the mother parenting model yielded several differences with the time 1 father model. In particular the association between gender and mother overprotection was constrained and not significant overall in the mother parenting model. Moreover, mother overprotection was not a significant direct predictor of PSU in either biological or adopted offspring in the mother model. The covariance path between support and care was not significant in this model.

Time 2 father parenting model. The fit indices for the time 2 father parenting model showed a good fit: $\chi^{2}=77.103 ; \mathrm{DF}=45 ; \mathrm{CFI}=0.96$; $\mathrm{RMSEA}=0.06 ; \mathrm{R}^{2}=0.07$ (see Figure 4). In this time 2 model, offspring's gender and age became significant direct predictors of PSU. Higher time 2 PSU scores were associated with male gender and younger age in both biological and adoptive samples. Monitoring, father positive parenting, father coercion, and father overprotection were no longer significant direct predictors for either group; however, cohesion was still a significant protective factor for the adoptive group.

Time 2 mother parenting model. The fit indices for the time 2 mother parenting model showed a moderately good fit: $\chi^{2}=94.950$; $\mathrm{DF}=45$; $\mathrm{CFI}=0.94$; $\mathrm{RMSEA}=0.07 ; \mathrm{R}^{2}=0.06$ (see Figure 5). By comparing this model with the time 1 mother model and father models, there are several noticeable differences. In the same manner as the time 2 father model, monitoring and positive parenting are no longer significant for either biological or adopted offspring; however, not only did cohesion remain significant, but also mother coercion and overprotection became significant though only for the adoptive group.

\section{Discussion}

The current study attempted to deepen our understanding of the relationship patterns between parenting styles, offspring's adoption status, and substance use for youth and young adults of the Vancouver Family Survey (VFS). It was intended to establish possible differences between father and mother parenting, biological and adoptive groups, and differences by time (maturation). This study also extends the hypothesis of the socialization theory (i.e., that offspring internalize norms and expectations learned through their interaction with parents at a young age and convey them to other contexts later in their lives).

Overall estimate data shows that environmental factors (parenting styles in the first 15 years of offspring's lives) have significant influences on PSU in adolescence (time 1), but these factors become less significant in a later life stage (time 2). $\mathrm{R}^{2}$ of both the time 1 father parenting model and time 1 mother parenting model are much higher than the time 2 father and mother models ( 0.18 and 0.15 versus 0.07 and 0.06 respectively). In the current study, variables such as monitoring, both father/mother positive parenting factors (cohesion, support, and care), and father overprotection, significantly predicted the PSU time 1; however, only offspring's gender and age showed significant paths to PSU at time 2 . These findings are consistent with the suggestions made by the behavioural genetic approach, namely that adolescents are more influenced by environmental factors than adults (e.g., Derringer et al., 2008). 
To examine if the influences of father's and mother's parenting styles are different, separate father and mother models were employed in the current study. Although both models appeared to be similar, father's and mother's parenting styles were shown to have differential influences in the current study. The influence of both father and mother overprotection were noteworthy. Since overprotection indicates fearfulness and anxiety for the safety of offspring, and may therefore engender guilt and be experienced as intrusive, it is suggested that this type of parenting might hinder the development of a sense of autonomy, and be linked to various psychological maladjustments and misbehaviours (Creemers et al., 2011). However, despite the findings of other studies that a higher level of parental overprotection is significantly associated with a higher risk of adolescent alcohol use (e.g., Visser, de Winter, Vollebergh, Verhulst, \& Reijneveld, 2013), in the current study, father overprotection was found to be a significant protective factor at time 1 in both groups, while mother overprotection was so for the adopted offspring group at time 2. One possible explanation for this contradictory finding could be ages of respondents in the current and other studies. At the time of parenting data collection, offspring in the VFS were aged between 14 and 25. Since all data on parenting styles were based on respondents' perspectives on their parents' parenting in the first 15 years of their lives, for most participants, their perspectives are retrospective in nature. However, participants in both the Creemers et al. (2011) and Visser et al. (2013) studies were younger (10 to 12 years of age) and reported "current" parenting practice at the data collection. It is possible that perception of the overprotection variable is developmentally sensitive and changes through time. This finding indicates that more studies with older adolescents and young adults need to be conducted in order to identify each parenting variable as a protective or risk factor.

Beyond what we have described above, we suggest that one of the most interesting and important contributions of our study is the comparison between biological and adopted offspring with regard to parental influences on their polysubstance use. Firstly, it appears that adopted offspring showed significant gender associations with five out of six parenting variables. This might suggest potential direct and indirect influences between male adopted offspring's PSU and their low perceived scores of positive parenting variables. Secondly, all four of our models consistently show the significant protective influence of family cohesion on PSU (time 1 and time 2) in the adoptive group. This is particularly interesting because cohesion showed no significant influence at all for the biological group. In summary, the adoptive group seemed to be more sensitive or more strongly influenced by various parenting styles and other familial environments than the biological group. It is also interesting that parenting styles keep influencing their adopted offspring even as they enter young adulthood. This finding is consistent with the findings of Enoch (2012) and Kendler et al. (2012). This could be explained by the socalled "differential susceptibility hypothesis" which claims that "genetic background may make some individuals more susceptible to good and bad environmental influences” (Enoch, 2012, p. 155) as well as by the developmental change in gene effect (Ducci et al., 2011).

The current study was not without limitations. Our monitoring variable does not allow us to examine how and why offspring provided information to their parents which became parental knowledge and ultimately "monitoring” in the current study. The measure could encompass parent-solicited information as well as voluntary disclosure by offspring based on the quality of the parent-child relationship (Bohnert et al., 2012; Kerr et al., 2010). 
Furthermore, it should not be overlooked that there is a two-way effect of upbringing between children and parents, since the characteristics of the child can facilitate or complicate the type of parenting style used by the parents (Barnes et al., 2006; Becoña et al., 2012). There is a possibility that a child's prior interest in or use of substances might have caused parents to increase their monitoring levels (Bohnert et al., 2012) and/or their psychological control (Albrecht, Galambos, \& Jansson, 2007). In addition, given that some parenting behaviours are subject to change during adolescent development and in reaction to the behaviour of the child (O’Connor, 2002), future studies need to focus on the change in parenting behaviours during adolescence and on the interplay between parenting and child characteristics (Albrecht et al., 2007; Creemers et al., 2011).

The findings from the current study suggest that parenting programs should pay close attention to positive parenting aspects such as monitoring (parental knowledge), cohesion, care, and support, as well as father involvement. Parents should be encouraged to be confidently involved in their offspring's development even as offspring get older. These findings will be useful for training programs for parents as well as for professionals working with children, youth, and families. Furthermore, based on the findings about the potential sensitivity and susceptibility of adopted offspring towards parenting and its long-term influence, it is crucial that all personnel who work with or live with adopted or foster children and youth are aware of the direct and indirect impact of parenting as well as that of the whole family environment. These personnel include professionals such as Child and Youth Care (CYC) workers and social workers, adoptive parents, foster parents, and other family members. Only if all professionals such as CYC workers as well as all parents including current and future adoptive or foster parents can easily access parenting programs as preventive and proactive measures, will we be more effective at reducing the prevalence of PSU than we are now by using reactive interventions and treatments for youth and young adults. 
International Journal of Child, Youth and Family Studies (2014) 5(3): 466-492

\section{References}

Albrecht, A. K., Galambos, N. L., \& Jansson, S. M. (2007). Adolescents’ internalizing and aggressive behaviors and perceptions of parents’ psychological control: A panel study examining direction of effects. Journal of Youth and Adolescence, 36(5), 673-684. doi: 10.1007/s10964-007-9191-5

Bahr, S., \& Hoffmann, J. (2010). Parenting style, religiosity, peers, and adolescent heavy drinking. Journal of Studies on Alcohol and Drugs, 71(4), 539-543. http///dx.doi.org/10.15288/jad.2010.71.539

Barnes, G. E., Anderson, R. E., \& Jansson, M. (2008, June). Polysubstance use and mental health symptoms. Paper presented at the $34^{\text {th }}$ Alcohol epidemiology Symposium of Kettil Bruun Society, Victoria, Canada.

Barnes, G. E., Jansson, M., \& Stockwell, T. (2011, July). Personality and substance use. Paper presented at the International Society for the Study of Individual Differences Conference, London, United Kingdom.

Barnes, G. E., Murray, R. P., Patton, D., Bentler, P., \& Anderson, R. E. (2000). The addictionprone personality. New York: Kluwer Academic/Plenum Publishers.

Barnes, G. E., Patton, D., Marshall, S. K. (1997). Family Environments and Substance Use. Final Report Submitted to NHRDP. Ottawa, Canada.

Barnes, G. M., \& Farrell, M. P. (1992). Parental support and control as predictors of adolescent drinking, delinquency, and related problem behaviors. Journal of Marriage and the Family, 54(4), 763-776. http://dx.doi.org/10.2307/353159

Barnes, G. M., Hoffman, J. H., Welte, J. W., Farrell, M. P., \& Dintcheff, B. A. (2006). Effects of parental monitoring and peer deviance on substance use and delinquency. Journal of Marriage and Family, 68(4), 1084-1104. doi: 10.1111/j.1741-3737.2006.00315.x

Becoña, E., Martínez, Ú., Calafat, A., Juan, M., Fernández-Hermida, J. R., \& Secades-Villa, R. (2012). Parental styles and drug use: A review. Drugs - Education Prevention and Policy, 19(1), 1-10. doi: 10.3109/09687637.2011.631060

Bentler, P. M. (2004). EQS 6.1 for Windows. Encino, CA: Multivariate Software Inc.

Bogenschneider, K., Wu, M., Raffaelli, M., \& Tsay, J. C. (1998). Parent influences on adolescent peer orientation and substance use: The interface of parenting practices and values. Child Development, 69(6), 1672-1688. doi: 10.1111/j.1467-8624.1998.tb06184.x

Bohnert, K., Anthony, J., \& Breslau, N. (2012). Parental monitoring at age 11 and subsequent onset of cannabis use up to age 17: Results from a prospective study. Journal of Studies on Alcohol and Drugs, 73(2), 173-177.http://dx.doi.org/10.15288/jsad.2012.73.173 
International Journal of Child, Youth and Family Studies (2014) 5(3): 466-492

Brière, F. N., Fallu, J., Descheneaux, A., \& Janosz, M. (2011). Predictors and consequences of simultaneous alcohol and cannabis use in adolescents. Addictive Behaviors, 36(7), 785788. http://dx.doi.org/10.1016/j.addbeh.2011.02.012

Byrne, B. M. (2012). Structural equation modeling with Mplus: Basic concepts, applications, and programming. New York: Routledge.

Cahalan, D., \& Cisin, I. H. (1968). American drinking practices: Summary of findings from a national probability sample ii measurement of massed versus spaced drinking. Quarterly Journal of Studies on Alcohol, 29(3), 642-656.

Cleveland, M. J., Feinberg, M. E., \& Greenberg, M. T. (2010). Protective families in high- and low-risk environments: Implications for adolescent substance use. Journal of Youth and Adolescence, 39(2), 114-126. doi: 10.1007/s10964-009-9395-y

Cleveland, M. J., Feinberg, M., Osgood, D., \& Moody, J. (2012). Do peers' parents matter? A new link between positive parenting and adolescent substance use. Journal of Studies on Alcohol and Drugs, 73(3), 423-433. http://dx.doi.org/10.15288/jsad.2012.73.423

Creemers, H. E., Harakeh, Z., Dick, D. M., Meyers, J., Vollebergh, W. A. M., Ormel, J., .. . Huizink, A. C. (2011). DRD2 and DRD4 in relation to regular alcohol and cannabis use among adolescents: Does parenting modify the impact of genetic vulnerability? The TRAILS study. Drug and Alcohol Dependence, 115(1-2), 35-42. doi: 10.1016/j.drugalcdep.2010.10.008

Derringer, J., Krueger, R., McGue, M., \& Iacono, W. (2008). Genetic and environmental contributions to the diversity of substances used in adolescent twins: A longitudinal study of age and sex effects. Addiction, 103(10), 1744-1744. http://dx.doi.org/10.1111/j.1360-0443.2008.02305.x

Dick, D. M., Prescott, C., \& McGue, M. (2009). The genetics of substance use and substance use disorders. (pp. 433-453). New York, NY: Springer New York. doi: 10.1007/978-0-38776727-7_29

Dorius, C., Bahr, S., Hoffmann, J., \& Harmon, E. (2004). Parenting practices as moderators of the relationship between peers and adolescent marijuana use. Journal of Marriage and Family, 66(1), 163-178. http://dx.doi.org/10.1111/j.0022-2445.2004.00011.x-i1

Ducci, F., Ekelund, J., Peltonen, L., Freimer, N., Elliott, P., Schumann, G., . . Hoggart, C. (2011). TTC12-ANKK1-DRD2 and CHRNA5-CHRNA3-CHRNB4 influence different pathways leading to smoking behavior from adolescence to mid-adulthood. Biological Psychiatry, 69(7), 650-660. doi: 10.1016/j.biopsych.2010.09.055

Enoch, M. (2012). The influence of Gene-Environment interactions on the development of alcoholism and drug dependence. Current Psychiatry Reports, 14(2), 150-158. doi: 10.1007/s11920-011-0252-9 
International Journal of Child, Youth and Family Studies (2014) 5(3): 466-492

Fergusson, D. M., Lynskey, M., \& Horwood, J. L. (1995). The adolescent outcomes of adoption: A 16- year longitudinal study. Journal of Child Psychology \& Psychiatry \& Allied Disciplines, 36(4), 597-616. http://dx.doi.org/10.1111/j.1469-7610.1995.tb01313.x

Hair, E. C., Moore, K. A., Garrett, S. B., Ling, T., \& Cleveland, K. (2008). The continued importance of quality parent-adolescent relationships during late adolescence. Journal of Research on Adolescence, 18(1), 187-200. doi: 10.1111/j.1532-7795.2008.00556.x

Jiménez-Iglesias, A., Moreno, C., Granado-Alcón, M. C., \& López, A. (2012). Parental knowledge and adolescent adjustment: Substance use and health-related quality of life. The Spanish Journal of Psychology, 15(1), 132-144. doi:

10.5209/rev_SJOP.2012.v15.n1.37297

Jones, R. M. (2011). Psychosocial development and first substance use in third and fourth grade students: A short-term longitudinal study. Child Development Research, 2011, 1-6. doi: $10.1155 / 2011 / 916020$

Kendler, K. S., Sundquist, K., Ohlsson, H., Palmér, K., Maes, H., Winkleby, M. A., \& Sundquist, J. (2012). Genetic and familial environmental influences on the risk for drug abuse: A national Swedish adoption study. Archives of General Psychiatry, 69(7), 690-697. doi: 10.1001/archgenpsychiatry.2011.2112

Kerr, M., Stattin, H., \& Burk, W. (2010). A reinterpretation of parental monitoring in longitudinal perspective. Journal of Research on Adolescence, 20(1), 39-64. doi: 10.1111/j.1532-7795.2009.00623.x

Lac, A., Alvaro, E. M., Crano, W. D., \& Siegel, J. T. (2009). Pathways from parental knowledge and warmth to adolescent marijuana use: An extension to the theory of planned behavior. Prevention Science: The Official Journal of the Society for Prevention Research, 10(1), 22-32. doi: 10.1007/s11121-008-0111-z

Latendresse, S. J., Rose, R. J., Viken, R. J., Pulkkinen, L., Kaprio, J., \& Dick, D. M. (2010). Examining the etiology of associations between perceived parenting and adolescents' alcohol use: Common genetic and/or environmental liabilities? Journal of Studies on Alcohol and Drugs, 71(3), 313-325. http:/dx.doi.org/10.15288/jsad.2010.71.313

O'Connor, T. G. (2002). Annotation: The 'effects' of parenting reconsidered: Findings, challenges, and applications. Journal of Child Psychology and Psychiatry, 43(5), 555572. doi: 10.1111/1469-7610.00046

Olson, D. H. \& Tiesel, J. (1991). Faces II: Linear scoring and interpretation. University of Minnesota St. Paul, MN. 
International Journal of Child, Youth and Family Studies (2014) 5(3): 466-492

Padilla-Walker, L. M., Bean, R. A., \& Hsieh, A. L. (2011). The role of parenting and personal characteristics on deviant peer association among European American and Latino adolescents. Children and Youth Services Review, 33(10), 2034-2042. doi: 10.1016/j.childyouth.2011.05.034

Pape, H., Rossow, I., \& Storvoll, E. E. (2009). Under double influence: Assessment of simultaneous alcohol and cannabis use in general youth populations. Drug and Alcohol Dependence, 101(1), 69-73. doi:10.1016/j.drugalcdep.2008.11.002

Parker, G., Tupling, H., \& Brown, L. B. (1979). A parental bonding instrument. British Journal of Medical Psychology, 52(1), 1-10.

Patock-Peckham, J., King, K., Morgan-Lopez, A., Ulloa, E., \& Moses, J. (2011). Gender-specific mediational links between parenting styles, parental monitoring, impulsiveness, drinking control, and alcohol-related problems. Journal of Studies on Alcohol and Drugs, 72(2), 247-258. http://dx.doi.org/10.15288/jsad.2011.72.247

Patrick, M. E., Wightman, P., Schoeni, R. F., \& Schulenberg, J. E. (2012). Socioeconomic status and substance use among young adults: A comparison across constructs and drugs. Journal of Studies on Alcohol and Drugs, 73(5), 772-782. http://dx.doi.org/10.15288/jsad.2012.73.772

Piko, B. F., \& Balázs, M. Á. (2012a). Authoritative parenting style and adolescent smoking and drinking. Addictive Behaviors, 37(3), 353-356. doi:10.1016/j.addbeh.2011.11.022

Piko, B. F., \& Balázs, M. A. (2012b). Control or involvement? Relationship between authoritative parenting style and adolescent depressive symptomatology. European Child \& Adolescent Psychiatry, 21(3), 149-155. doi: 10.1007/s00787-012-0246-0

Piko, B. F., \& Kovács, E. (2010). Do parents and school matter? Protective factors for adolescent substance use. Addictive Behaviors, 35(1), 53-56. http://dx.doi.org/10.1016/j.addbeh.2009.08.004

Plomin, R., \& Colledge, E. (2001). Genetics and psychology: Beyond heritability. European Psychologist, 6(4), 229-240. doi: 10.1037/1016-9040.6.4.229

Pougnet, E., Serbin, L. A., Stack, D. M., \& Schwartzman, A. E. (2011). Fathers' influence on children's cognitive and behavioural functioning: A longitudinal study of Canadian families. Canadian Journal of Behavioural Science/Revue Canadienne Des Sciences Du Comportement, 43(3), 173-182. doi: 10.1037/a0023948

Ryan, S. M., Jorm, A. F., \& Lubman, D. I. (2010). Parenting factors associated with reduced adolescent alcohol use: A systematic review of longitudinal studies. Australian and New Zealand Journal of Psychiatry, 44(9), 774-783. doi: 10.1080/00048674.2010.501759

Schensul, J. J., Convey, M., \& Burkholder, G. (2005). Challenges in measuring concurrency, agency and intentionality in polydrug research. Addictive Behaviors, 30(3), 571-574. doi:10.1016/j.addbeh.2004.05.022 
International Journal of Child, Youth and Family Studies (2014) 5(3): 466-492

Visser, L., de Winter, A., Vollebergh, W., Verhulst, F., \& Reijneveld, S. (2013). The impact of parenting styles on adolescent alcohol use: The TRAILS study. European Addiction Research, 19(4), 165-172. doi:10.1159/000342558

Wadsworth, S. J., Corley, R. P., Defries, J. C., Fulker, D. W., Carey, G. \& Plomin, R. (1997). Substance experimentation in the Colorado Adoption Project. Personality and Individual Differences, 23(3), 463-471. http://dx.doi.org/10.1016/s0191-8869(97)00050-0

Zeinali, A., Sharifi, H., Enayati, M., Asgari, P., \& Pasha, G. (2011). The mediational pathway among parenting styles, attachment styles and self-regulation with addiction susceptibility of adolescents. Journal of Research in Medical Sciences, 16(9), 1105-1121. 
International Journal of Child, Youth and Family Studies (2014) 5(3): 466-492

Table 1. Parenting styles and PSU patterns by adoption status and gender (MANOVA)

\begin{tabular}{|c|c|c|c|}
\hline \multirow[t]{2}{*}{ Dependent variable } & \multicolumn{3}{|c|}{$\mathrm{F}$} \\
\hline & Adoption status & Gender & Adoption X Gender \\
\hline \multicolumn{4}{|l|}{ Multivariate test } \\
\hline Parenting styles & $2.30 *$ & $2.44 * *$ & 1.38 \\
\hline Substance use & $13.47 * * *$ & $3.84^{*}$ & 1.89 \\
\hline \multicolumn{4}{|l|}{ Between subject effects } \\
\hline \multicolumn{4}{|l|}{ Parenting styles } \\
\hline Cohesion & $7.24^{* *}$ & $4.34^{*}$ & $7.86 * *$ \\
\hline Monitoring & $10.17 * *$ & $8.66 * *$ & .06 \\
\hline Mother Support & 1.46 & 1.32 & 2.24 \\
\hline Father Support & .86 & 3.04 & $9.44 * *$ \\
\hline Mother Coercion & $4.93 *$ & $4.57 *$ & .03 \\
\hline Father Coercion & $4.90 *$ & $5.56 *$ & .35 \\
\hline Mother Care & 1.77 & .52 & 2.35 \\
\hline Father Care & .38 & $6.38 *$ & $6.08 *$ \\
\hline Mother Overprotection & .60 & .40 & .01 \\
\hline Father Overprotection & .00 & .53 & .70 \\
\hline \multicolumn{4}{|l|}{ Substance use } \\
\hline PSU T1 & $18.88 * * *$ & 3.62 & 3.74 \\
\hline PSU T2 & $22.03 * * *$ & $7.36 * *$ & 1.39 \\
\hline
\end{tabular}

Table 2. Comparisons of mean scores by adoption status and gender

\begin{tabular}{lcccc}
\hline & \multicolumn{2}{c}{ Adopted offspring } & \multicolumn{2}{c}{ Biological offspring } \\
\cline { 2 - 5 } & $\begin{array}{c}\text { Male } \\
\text { Mean }\end{array}$ & $\begin{array}{c}\text { Female } \\
\text { Mean }\end{array}$ & $\begin{array}{c}\text { Male } \\
\text { Mean }\end{array}$ & $\begin{array}{c}\text { Female } \\
\text { Mean }\end{array}$ \\
\hline Cohesion & 2.97 & 3.88 & 3.97 & 3.84 \\
Father Support & 11.47 & 13.54 & 13.14 & 12.51 \\
Father Care & 21.58 & 26.37 & 24.39 & 24.57 \\
\hline
\end{tabular}


International Journal of Child, Youth and Family Studies (2014) 5(3): 466-492

Table 3. Correlations between demographic variables, parenting variables and polysubstance use

\begin{tabular}{|c|c|c|c|c|c|c|c|c|c|c|c|c|c|c|c|}
\hline & & 1 & 2 & 3 & 4 & 5 & 6 & 7 & 8 & 9 & 10 & 11 & 12 & 13 & 14 \\
\hline 1 & Gender & - & .07 & .04 & $-.17 \dagger$ & .09 & .02 & $.12^{*}$ & $.14^{*}$ & -.01 & .04 & -.10 & .04 & -.00 & $.12 *$ \\
\hline 2 & Age & -.14 & - & .04 & -.03 & -.04 & .02 & .03 & .05 & -.07 & .09 & -.07 & -.07 & .04 & $-.11^{*}$ \\
\hline 3 & Cohesion & $-.26 *$ & .11 & - & $.32 \ddagger$ & $.55 \ddagger$ & $.50 \ddagger$ & $-.14^{*}$ & $-.18 \dagger$ & $.58 \ddagger$ & $.48 \neq$ & $-.20 \ddagger$ & $-.23 \ddagger$ & $-.17 \dagger$ & -.06 \\
\hline 4 & Monitoring & -.16 & -.13 & $.35 \dagger$ & - & $.20 \ddagger$ & $.37 \ddagger$ & $-.16 \dagger$ & $-.22 \ddagger$ & $.17 \dagger$ & $.24 \ddagger$ & -.05 & -.04 & $-.27 \ddagger$ & $-.13^{*}$ \\
\hline 5 & $\begin{array}{l}\text { Father } \\
\text { Support }\end{array}$ & $-.29 *$ & -.05 & $.53 \ddagger$ & $.42 \ddagger$ & - & $.50 \ddagger$ & -.10 & -.06 & $.75 \ddagger$ & $.30 \ddagger$ & $-.17 \dagger$ & -.10 & -.08 & -.02 \\
\hline 6 & $\begin{array}{l}\text { Mother } \\
\text { Support }\end{array}$ & -.17 & -.03 & $.47 \ddagger$ & $.36^{*}$ & $.52 \ddagger$ & - & $-.14^{*}$ & $-.30 \ddagger$ & $.37 \ddagger$ & $.70 \ddagger$ & $-.16 \dagger$ & $-.27 \ddagger$ & $-.18 \dagger$ & -.04 \\
\hline 7 & $\begin{array}{l}\text { Father } \\
\text { Coercion }\end{array}$ & .18 & -.12 & -.18 & -.17 & $-.23 *$ & $-.27 *$ & - & $.47 \ddagger$ & $-.27 \ddagger$ & $-.14^{*}$ & $.39 \ddagger$ & $.12^{*}$ & $.14^{*}$ & .08 \\
\hline 8 & $\begin{array}{l}\text { Mother } \\
\text { Coercion }\end{array}$ & .14 & -.15 & $-.30 \dagger$ & -.09 & .21 & $-.41 \ddagger$ & $.50 \ddagger$ & - & $-.14 *$ & $-.42 \ddagger$ & $.24 \ddagger$ & $.40 \ddagger$ & $.23 \ddagger$ & .11 \\
\hline 9 & $\begin{array}{l}\text { Father } \\
\text { Care }\end{array}$ & $-.30 \dagger$ & .05 & $.63 *$ & $.34 \dagger$ & $.83 \ddagger$ & $.45 \ddagger$ & $-.27 *$ & $-.27 *$ & - & $.43+$ & $-.30 \ddagger$ & $-.21 \neq$ & $-.18 \dagger$ & -.03 \\
\hline 10 & $\begin{array}{l}\text { Mother } \\
\text { Care }\end{array}$ & -.16 & .17 & $.59 \ddagger$ & $.34 \dagger$ & $.44 \ddagger$ & $.78 \ddagger$ & $-.33 \dagger$ & $-.50 \ddagger$ & $.60 \ddagger$ & - & $-.35 \ddagger$ & $-.50 \ddagger$ & $-.21 \ddagger$ & -.08 \\
\hline 11 & $\begin{array}{l}\text { Father } \\
\text { Overprotection }\end{array}$ & .04 & -.14 & $-.29 *$ & $-.28 *$ & $-.28 *$ & $-.36 \dagger$ & $.39 \ddagger$ & $.38 \dagger$ & $-.39 \dagger$ & $-.54 \ddagger$ & - & $.55 \ddagger$ & -.04 & -.03 \\
\hline 12 & $\begin{array}{l}\text { Mother } \\
\text { Overprotection }\end{array}$ & .08 & -.09 & $-.31 \dagger$ & $-.30 *$ & $-.26 *$ & $-.42 \ddagger$ & .11 & $.49 \ddagger$ & $-.34 \dagger$ & $-.54 \ddagger$ & $.55 \ddagger$ & - & .05 & .09 \\
\hline 13 & PSU T1 & .19 & .05 & $-.40 \ddagger$ & $-.46 \ddagger$ & $-.23 *$ & -.22 & .06 & .08 & $-.27 *$ & $-.28 *$ & .07 & .14 & - & $.55+$ \\
\hline 14 & PSU T2 & .16 & -.15 & $-.33 *$ & -.11 & $-.26^{*}$ & -.13 & .09 & -.19 & $-.33 \dagger$ & $-.26^{*}$ & .09 & .09 & $.49 \ddagger$ & - \\
\hline
\end{tabular}

PSU: Standardized Polysubstance use

Correlation coefficients for adopted offspring are below the diagonal; for biological offspring are above the diagonal ${ }^{*} p<.05 ; \dagger p<.01 ; \ddagger p<.00$ 
International Journal of Child, Youth and Family Studies (2014) 5(3): 466-492

Figure 1. Conceptual Model for data analysis

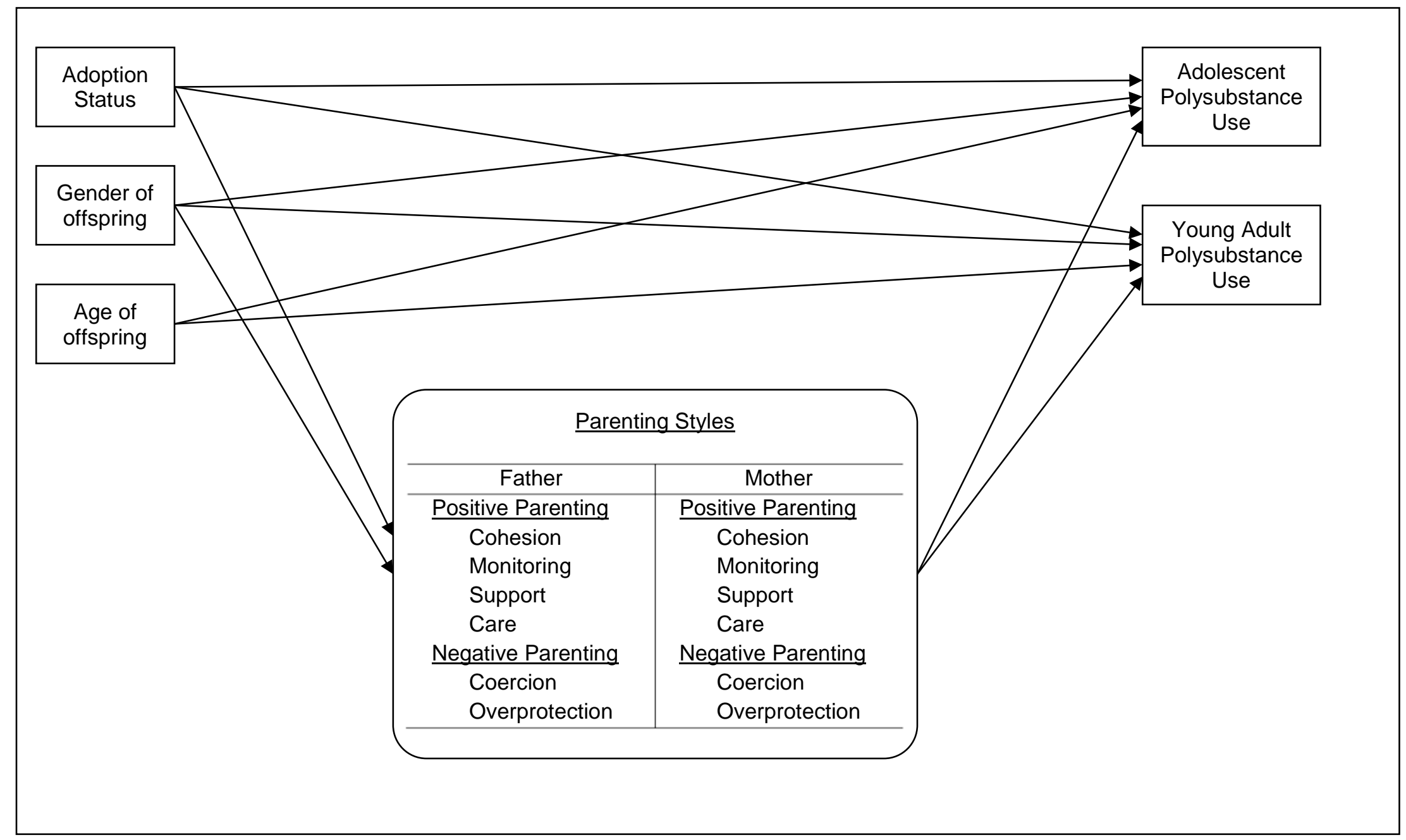


Figure 2. Time 1 Father parenting model

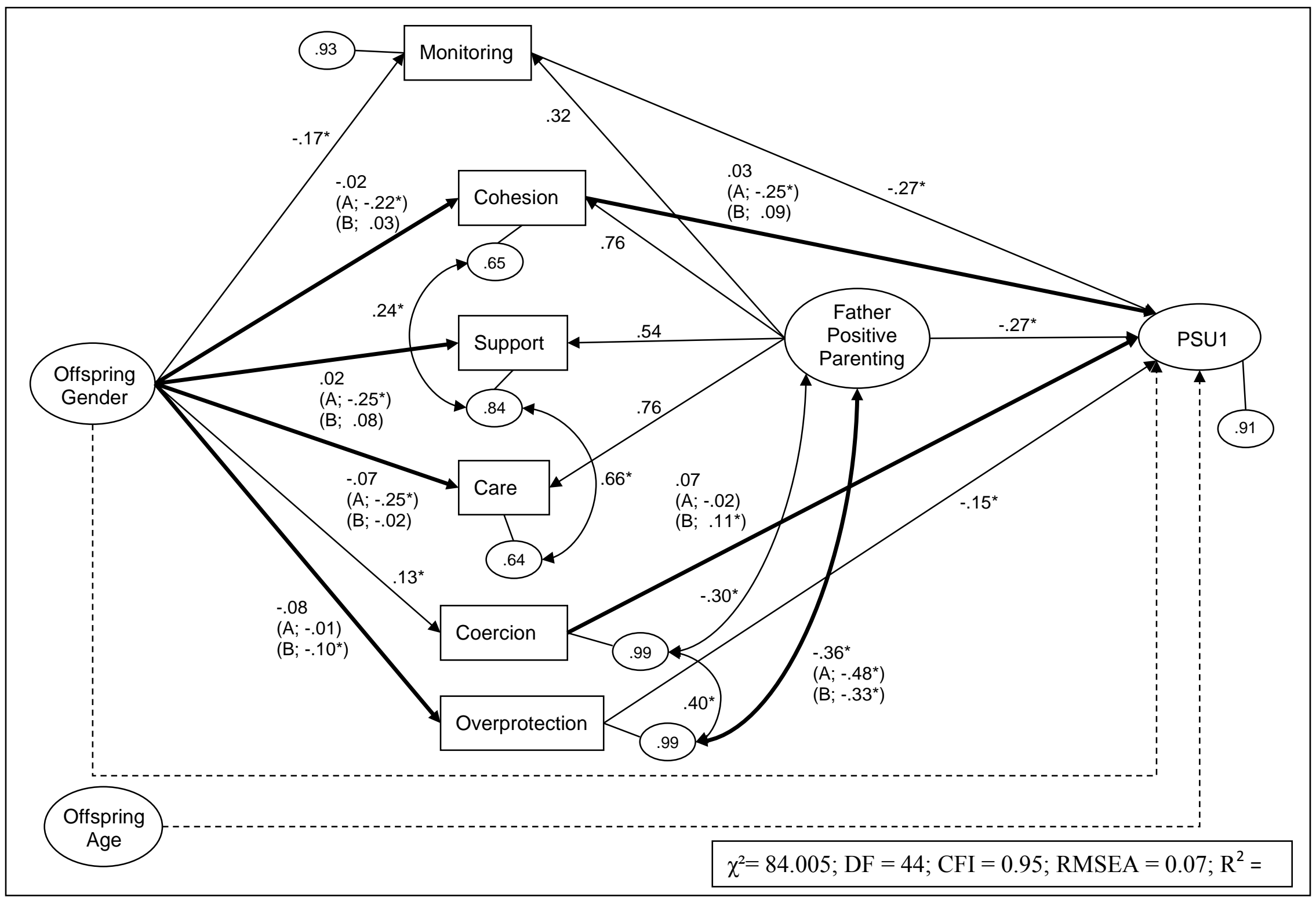


Figure 3. Time 1 Mother parenting model

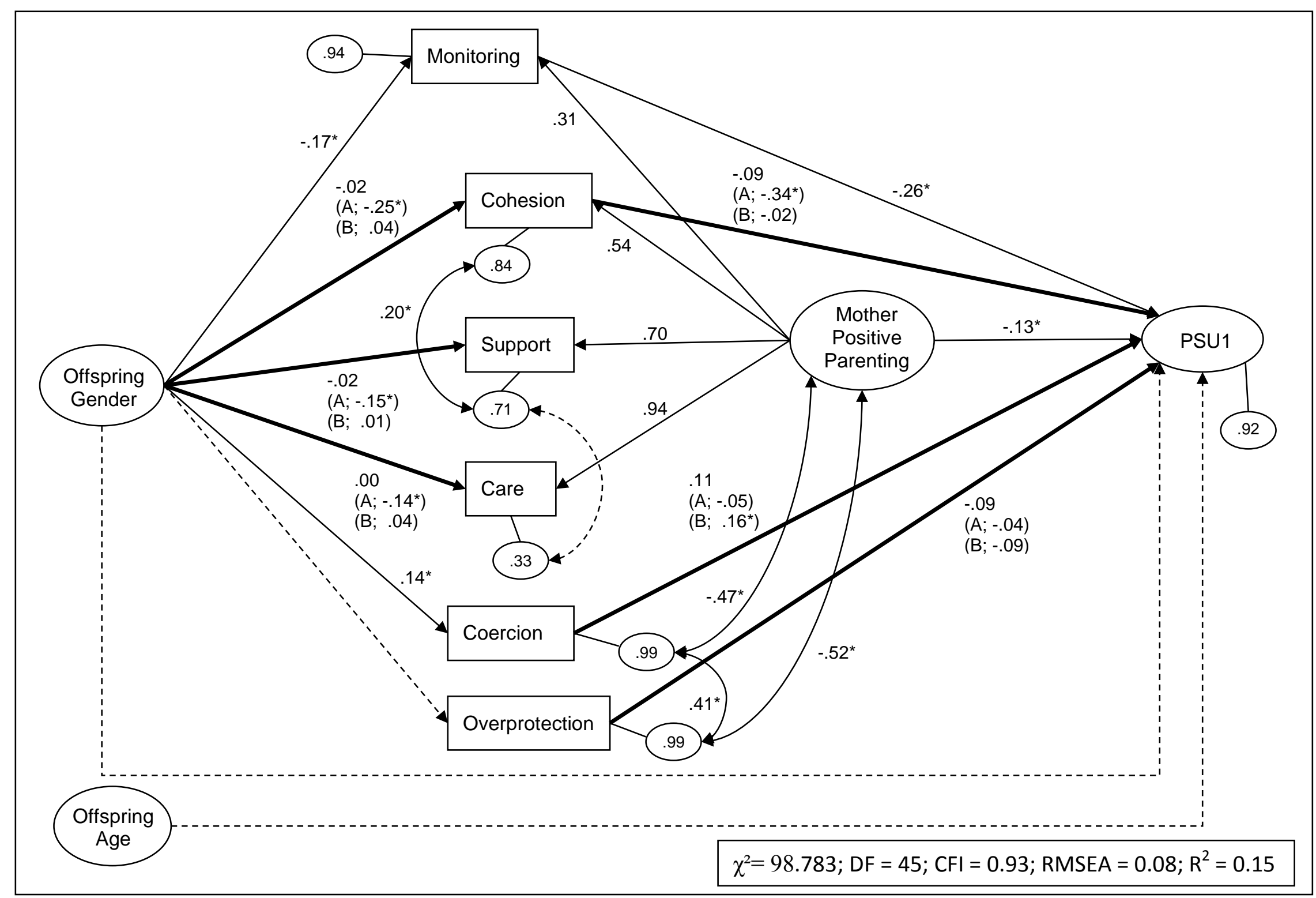


Figure 4. Time 2 Father parenting model

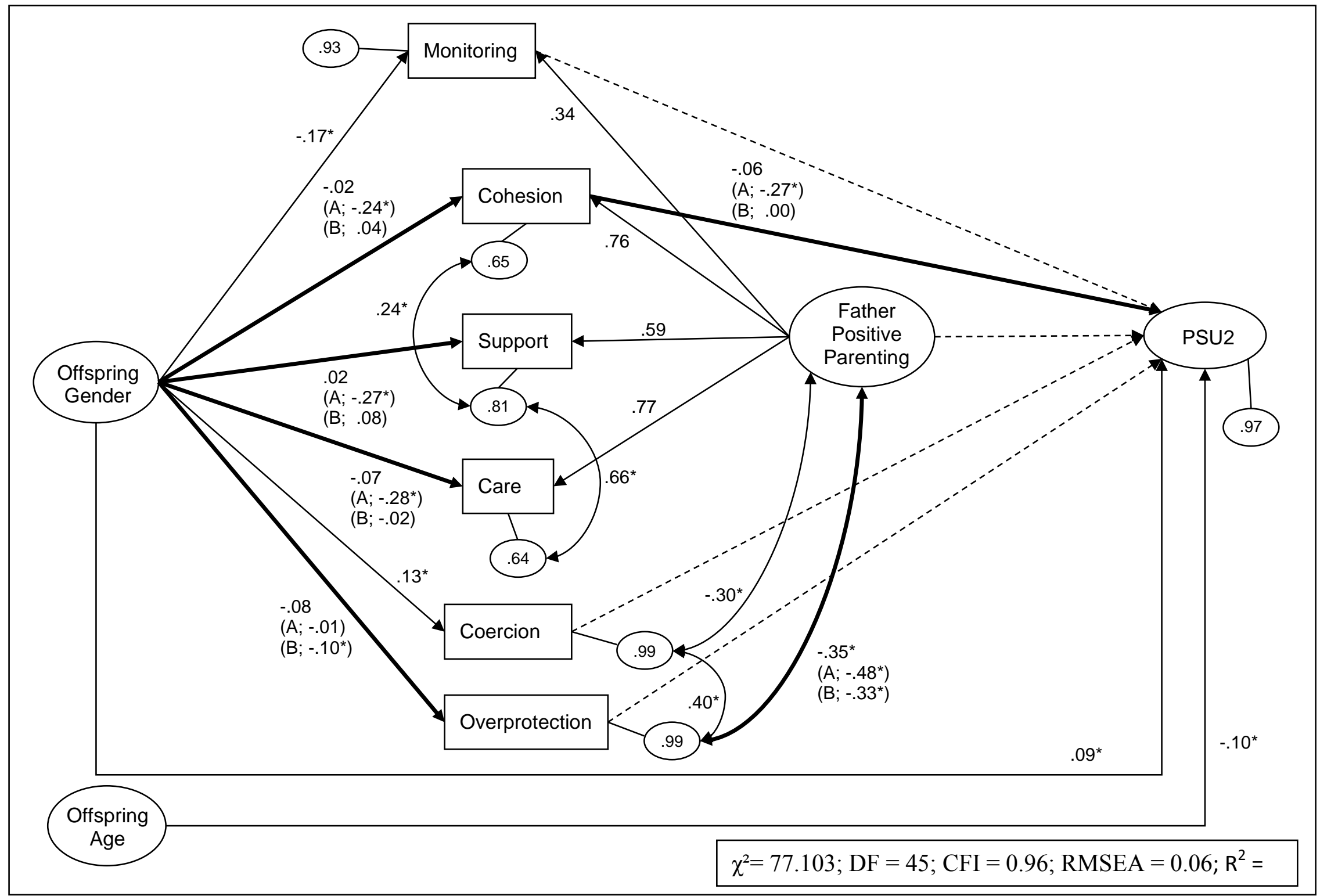


Figure 5. Time 2 Mother parenting model

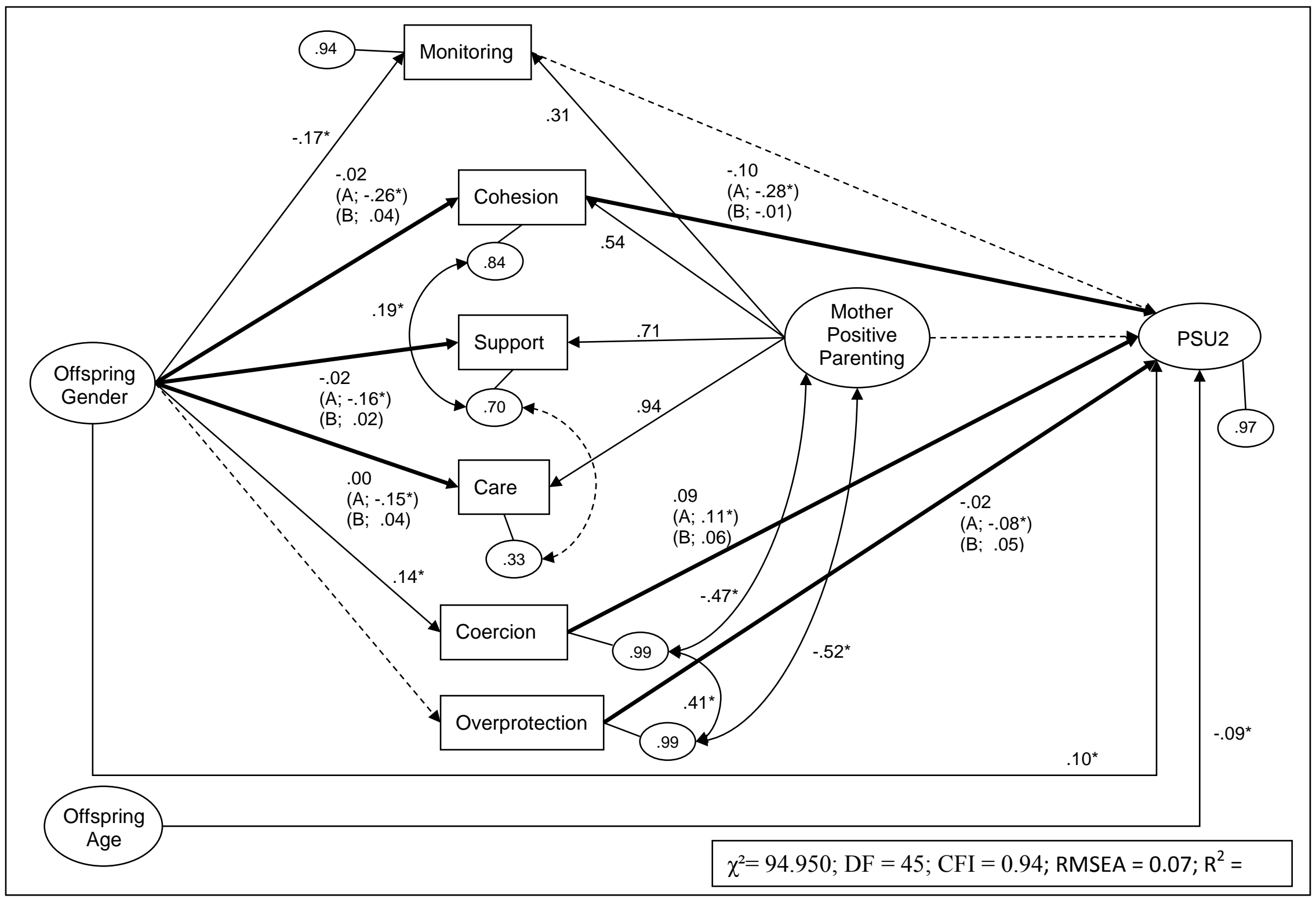

